\title{
OPTIMASI TEMPERATUR INTERFACE PADA PELAPISAN ULANG NI-HARD 1 DENGAN METODE GRAVITY CASTING
}

\author{
Kus Hanaldi ${ }^{1}$, Wiwik Purwadi², Friya Kurnia Nurzaenal ${ }^{3}$ \\ 1,2,3 Politeknik Manufaktur Negeri Bandung \\ E-mail : adihanaldi@gmail.com¹,wiwik@polman-bandung.ac.id ${ }^{2}$
}

\begin{abstract}
Abstrak
Grinding roll adalah salah satu jenis bimetallic casting, terdiri dari dua jenis material yang disatukan dengan metoda pengecoran. Grinding roll memiliki dua sifat material yang berbeda, bagian luar grinding roll harus keras karena akan menghancurkan material tambang atau batuan yang kekerasannya mencapai 9,3 mohs. Bagian dalam grinding roll haruslah lunak, selain untuk proses permesinan untuk pemasangan, juga digunakan untuk meredam getaran yang terjadi akibat proses penggilingan. Pada penggunaannya, lapisan luar grinding roll ini akan mengalami penipisan. Tujuan dari penelitian ini untuk memperbaiki balok $\mathrm{Ni}$-Hard 1 dengan melapisinya menggunakan material $\mathrm{Ni}$ Hard 1 cair dengan variabel bebas temperatur interface. Metodologi penelitian ini adalah balok $\mathrm{Ni}$ Hard 1 yang akan dilapisi (die blank) dipanaskan oleh aliran (flushing) Ni-Hardl cair pada permukaan die blank yang dilapisi. Volume cairan flushing ditampung pada bak pembuangan. Rancangan yang telah ditentukan disimulasikan menggunakan perangkat lunak solidcast 8.2 untuk mengetahui temperatur interface, lalu dilakukan percobaan di lapangan dan ikatan yang terjadi dianalisa dengan pengujian mikrostruktur, komposisi, dan kekerasan. Hasil dari penelitian ini adalah teknologi untuk melapisi $\mathrm{Ni}$-Hard 1 dengan material $\mathrm{Ni}$-Hard 1 yang pada permukaan gabungannya terjadi ikatan. Hasil penelitian yang dilakukan menunjukkan metode perbaikan dengan gravity casting dapat diaplikasikan pada benda Grinding roll, dengan variabel temperatur interface yang harus dicapai antara $887^{\circ} \mathrm{C}-1198{ }^{\circ} \mathrm{C}$, flushing time antara 10 - 20 detik, dengan temperatur pouring antara $1438{ }^{\circ} \mathrm{C}-1468$ ${ }^{\circ} \mathrm{C}$.
\end{abstract}

Kata Kunci: grinding roll, ni-hard 1, gravity casting, die blank, flushing

\begin{abstract}
Grinding roll is one type of product made by the method of bimetallic casting. The product consists of two types of material that held together with foundry process. Grinding roll has two kinds of different material properties, outer grinding roll should be hard because it would destroy the mine or rock with material hardness at 9.3 mohs. The inside of the grinding roll should be soft, for machining process, and also for dampen the vibration caused by the grinding process. In use, the outer layer of the grinding roll will be thinned. The purpose of this study to fix the beam Ni-Hard 1 by coating using a material Ni-Hard 1 with variable temperature liquid interface. The methodology of this study is the beam of Ni-Hard 1 to be coated (called die blank) is heated by the flow of liquid metal Ni Hard1. This process is called flushing. The volume of flushing fluid is accommodated at the disposal basin. The design, which has been determined, simulated using software (solidcast 8.2) to determine the temperature of interface, and then carried out experiments in the workshop.The bond was analyzed by testing the microstructure, composition, and hardness. Results from this study is the technology to coat $\mathrm{Ni}$-Hard 1 with material Ni-Hard 1 that bonding occurs at the surface. Results of research showed that surface fixing with gravity casting method can be applied at Grinding roll, with the temperature variable interface that must be achieved between $887^{\circ} \mathrm{C}-1198^{\circ} \mathrm{C}$, flushing time between 10-20 seconds, with a pouring temperature of $1438^{\circ} \mathrm{C}-1468^{\circ} \mathrm{C}$.
\end{abstract}

Keywords: grinding roll, ni-hard 1, gravity casting, die blank, flushing 


\section{PENDAHULUAN}

Pada umumnya perbaikan lapisan luar Grinding roll yang mengalami penipisan lapisan pada permukaan kerjanya menggunakan metode pengelasan. Metode ini memerlukan waktu yang relatif lama dan menghasilkan jenis ikatan fusi sehingga hasil perbaikan dengan proses pengelasan memiliki daya tahan yang lebih rendah daripada grinding roll yang baru hasil casting.

Perbaikan dengan proses gravity casting yang memanfaatkan flushing cairan pada permukaan kerja diharapkan terjadi ikatan difusi pada interface. Ikatan difusi dikendalikan oleh tiga parameter proses yang penting, yaitu : suhu, tekanan, dan waktu penahanan, tiga parameter tersebut saling berkaitan dalam artian memiliki efek satu sama lain. Suhu ikatan harus antara $50 \%$ sampai $70 \%$ dari titik leleh salah satu material yang titik lelehnya terendah

Ikatan difusi menawarkan banyak keuntungan terutama pada kekuatan ikatan yang hampir sama dengan logam dasar dan struktur mikro di daerah ikatan yang persis sama dengan logam induk.[2] Penelitian ini fokus untuk mengetahui temperatur interface yang tepat untuk melapisi ulang $\mathrm{Ni}$-Hard 1 oleh material $\mathrm{Ni}$-Hard 1 .

\section{TINJAUAN PUSTAKA}

Bimetallic casting dirancang untuk memungkinkan menyambung dengan mengandalkan efek pengelasan, dan bagian yang terbuat dari besi cor kromium untuk mendapatkan kekerasan tinggi dan ketahanan abrasive, namun keterbatasan dari metode ini adalah kebutuhan untuk memanaskan die blank yang ditempatkan dalam cetakan. metode ini dilakukan dengan bentuk dua sistem saluran seperti pada gambar 1 dan gambar 2. [3]

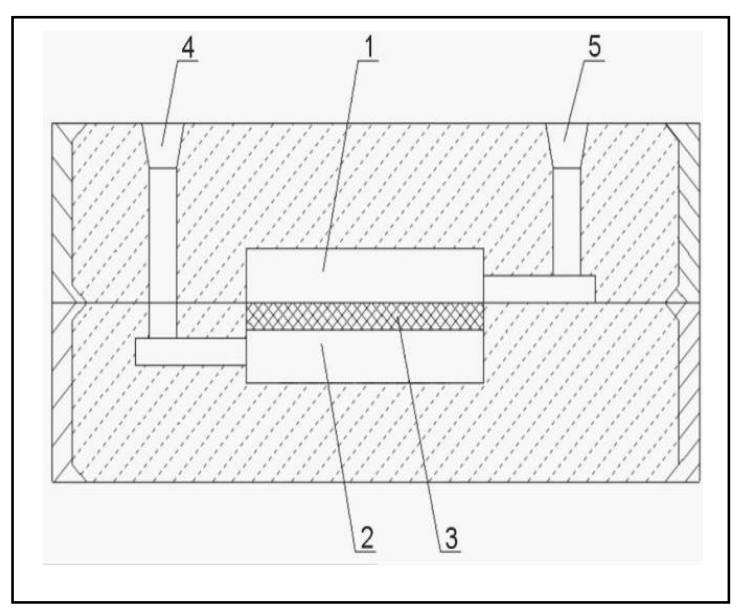

Gambar 1. Teknologi bimetallic layer casting dengan menggunakan 2 sistem saluran : 1-lapisan cast iron (layer), 2-rongga cetak (pemanas), 3-plat baja (die blank), 4 \& 5-saluran.

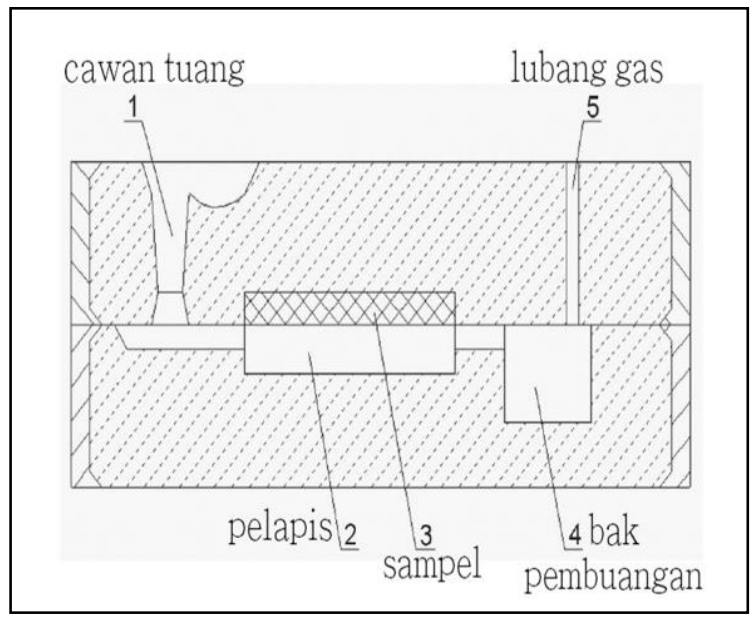

Gambar 2. Teknologi bimetallic layer casting dengan menggunakan bak pembuangan.

\section{III.METODE}

\section{III.1. Penentuan Variabel Penelitian}

Variable yang akan di tetapkan adalah sebagai berikut:

a. Variabel tetap

- Material die blank \& layer : : Ni-Hard 1

Tabel 1 Komposisi kimia Ni Hard 1 [4]

\begin{tabular}{|c|c|}
\hline Unsur & kadar (\%) \\
\hline $\mathrm{C}$ & $3,0-3,6$ \\
\hline $\mathrm{Si}$ & $0,3-0,5$ \\
\hline $\mathrm{Mn}$ & $0,3-0,7$ \\
\hline $\mathrm{S}$ & $\max 0,15$ \\
\hline $\mathrm{P}$ & $\max 0,15$ \\
\hline $\mathrm{Ni}$ & $3,3-3,8$ \\
\hline $\mathrm{Cr}$ & $1,5-2,6$ \\
\hline $\mathrm{Mo}^{*}$ & $0-0,04$ \\
\hline
\end{tabular}

- Temperatur cor $\left({ }^{\circ} \mathrm{C}\right) \quad: 1430-1470$

- Jenis pasir cetak : Greensand

- Dimensi rangka cetak $(\mathrm{mm}) \quad: 570 \times 440 \times 200$

- Rancangan

b. Variabel bebas

Variabel bebas pada penelitian ini adalah temperatur interface.

\section{III.2. Penentuan Alternatif Rancangan}

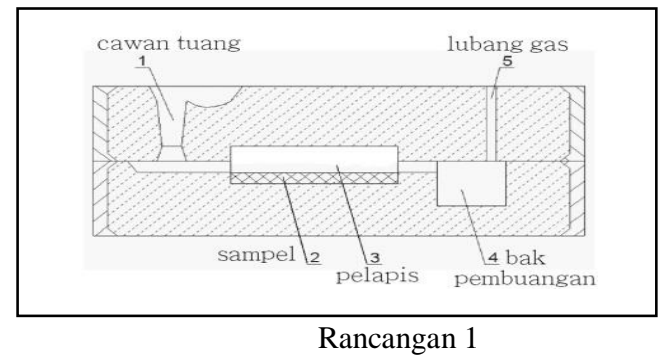




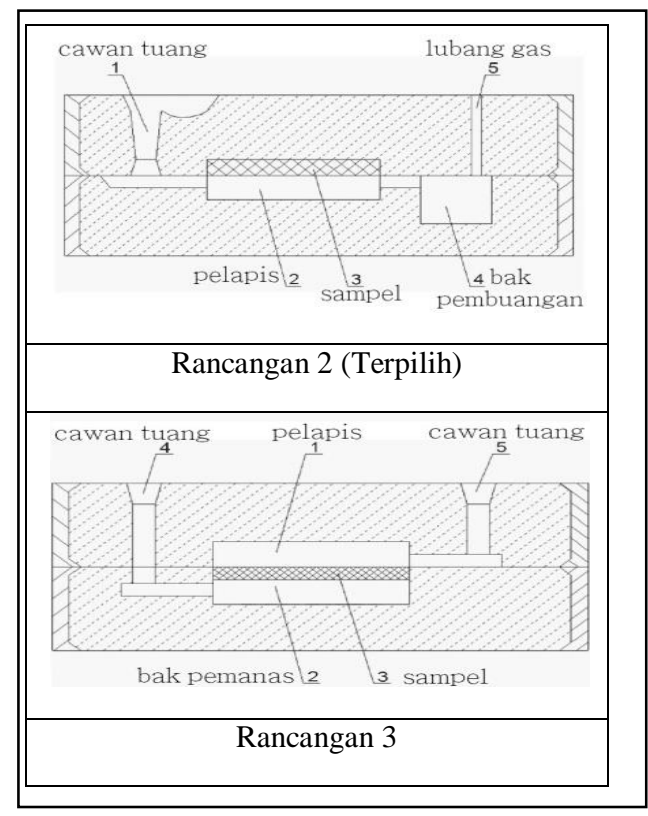

Gambar 3. Alternatif rancangan

Rancangan 2 terpilih karena area interface pada die blank menerima panas langsung dari cairan logam yang dicor. Turbulensi hanya terjadi sampai rongga layer penuh sehingga resiko erosi cetakan sangat rendah. Proses flushing optimal karena aliran yang laminar di area interface dan temperatur tertinggi terdapat di area interface. Ada proses pemanasan awal sebelum terjadi flushing akibat dari pengisian rongga pelapis yang berada di bagian bawah. Bak pembuangan pada rancangan dapat digantikan dengan ladle, cairan yang seharusnya mengisi bak buang dialirkan ke luar cetakan lalu masuk ke ladle. Cairan logam yang di tampung pada ladle dapat di kembalikan ke tanur untuk proses pouring selanjutnya, sehingga menghemat energi listrik proses peleburan. Karena rancangan 2 yang terpilih maka temperatur interface dikontrol oleh lamanya proses flushing.

\section{HASIL DAN PEMBAHASAN}

\section{IV.1. Rancangan Benda dan Sistem Saluran}

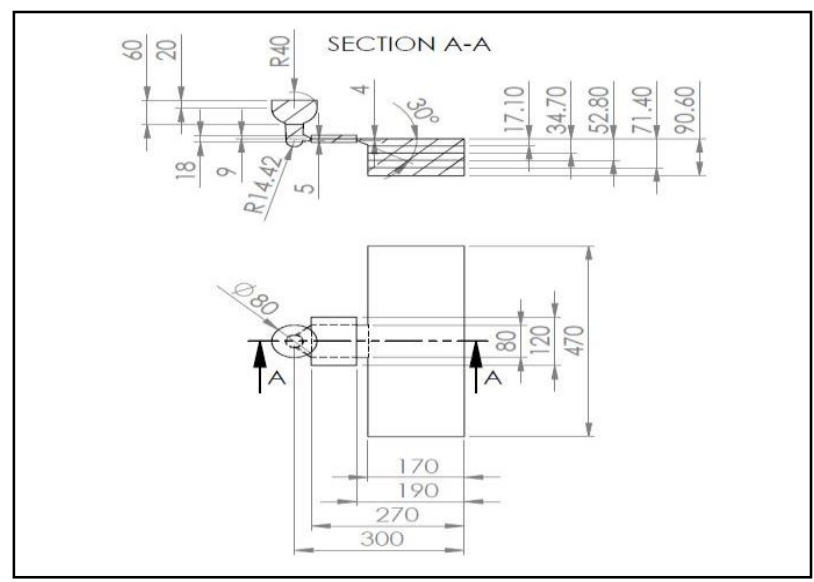

Gambar 4. Rancangan gambar teknik benda

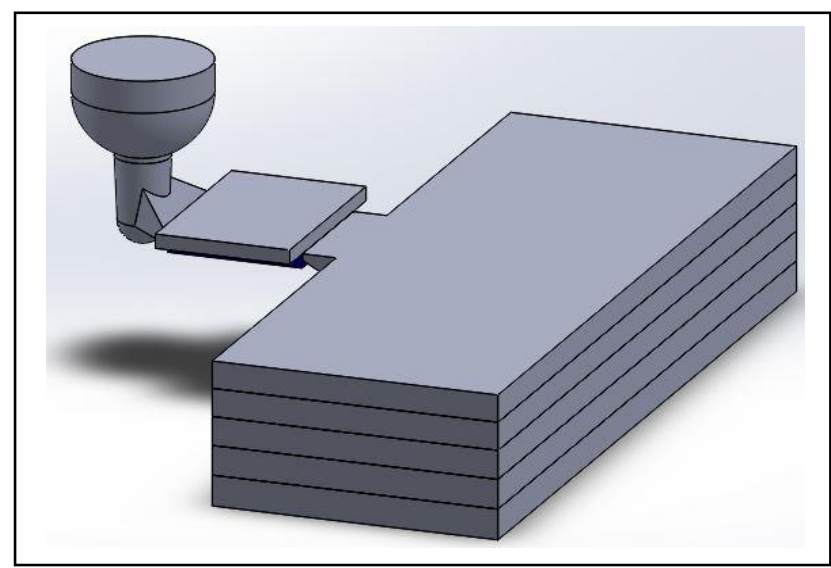

Gambar 5. Visual 3D hasil rancangan

Perancangan dimensi die blank dan pelapis dipengaruhi oleh kebutuhan aktual dimensi grinding roll yang akan diperbaiki/dilapisi dimana memiliki perbandingan ketebalan $1: 1$ antara bagian outer layer yang terkikis dengan ketebalan grinding roll yang akan dilapisi. Dimensi bak pembuangan ditentukan berdasarkan ukuran rangka cetak yang akan digunakan, bak pembuangan di rancang sebagai bagian lepas agar lebih efektif dan efisien. Dimensi sistem saluran ditentukan dari hasil perhitungan casting keseluruhan.

\section{IV.2.Hasil Simulasi FlushingTtime Terhadap Temperatur Interface}

Simulasi pengecoran menggunakan perangkat lunak solidcast 8.2 dilakukan untuk mengetahui temperatur interface yang terjadi akibat dari penggunaan flushing time yang berbeda. Hasil simulasi digunakan sebagai parameter batas atas dan batas bawah variabel bebas flushing time pada penelitian ini.

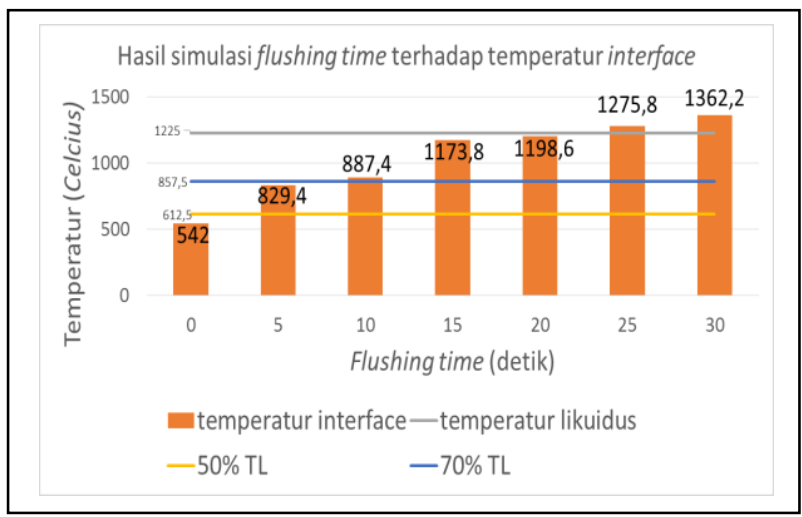

Gambar 6. Hasil simulasi flushing time terhadap temperatur interface

Hasil simulasi menunjukkan bahwa 50\% TL (Temperatur Likuidus) sebagai syarat terjadinya ikatan difusi tidak dapat dicapai tanpa flushing. Pada saat flushing time 5 detik, temperatur interface yang terjadi 
adalah $829,2{ }^{\circ} \mathrm{C}(67,7 \mathrm{TL})$ maka dari itu flushing time 5 detik dijadikan batas bawah pada penelitian ini. Pada saat flushing time 25 detik, temperatur interface yang terjadi diatas temperatur likuidus yaitu $1275^{\circ} \mathrm{C}(\mathrm{TL}=$ $1225^{\circ} \mathrm{C}$ ). maka dari itu, flushing time 25 detik dijadikan batas atas pada penelitian ini.

\section{IV.3. Pola}

Pola digunakan sebagai alat bantu untuk membuat rongga cetak pada cetakan pasir. Setelah proses pemadatan pasir cetak, pola tersebut dicabut / dilepaskan dari cetakan pasir yang kemudian akan meninggalkan rongga cetak.

Berikut ini adalah gambar dari pola yang digunakan pada penelitian ini:

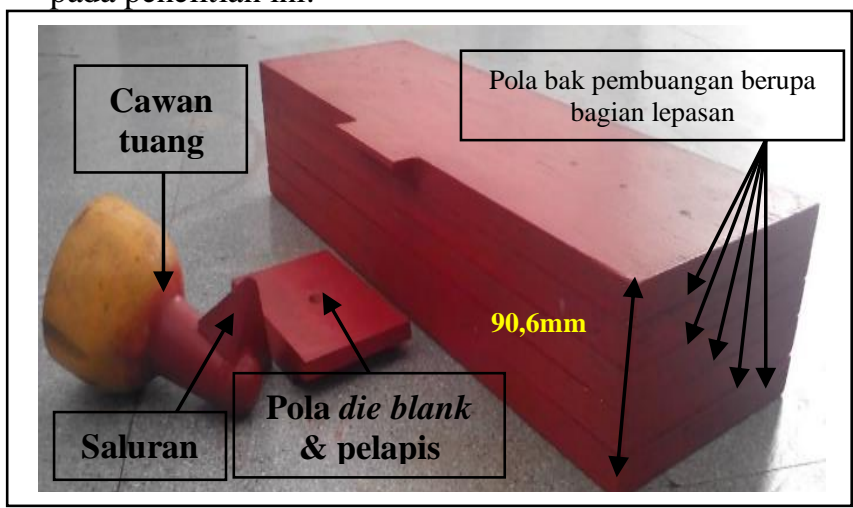

Gambar 7. Pola sistem saluran, die blank, pelapis, dan bak pembuangan

\section{IV.4. Cetakan}

Pasir cetak yang digunakan pada percobaan ini adalah green sand, selain ketersediaan yang banyak dan harga yang murah, pasir jenis ini memiliki daya hantar panas yang rendah, sehingga pemanasan area interface lebih efektif. Gambar tampak atas dari cetakan adalah sebagai berikut:

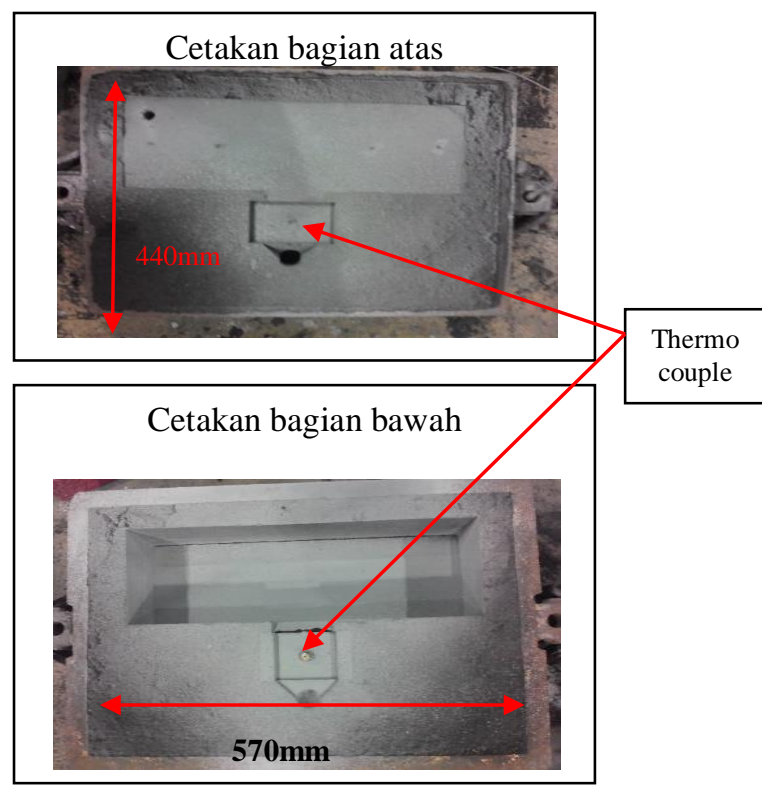

Gambar 8 Cetakan

\section{IV.5. Benda Cor (Casting)}

Setelah cetakan dicor menggunakan material $\mathrm{Ni}$ Hard 1 dan didinginkan didalam cetakan, kemudian cetakan dibongkar dengan menggunakan shake out machine. Selanjutnya cetakan dibersihkan menggunakan mesin shootblasting, setelah itu bagian bagian benda dipisahkan dari sistem saluran dan bak pembungan menggunakan gerinda tangan pemotong, lalu diratakan menggunakan gerinda tangan perata.

Gambar benda cor sebelum dipisahkan dari sistem saluran disajikan pada gambar 9 berikut ini:

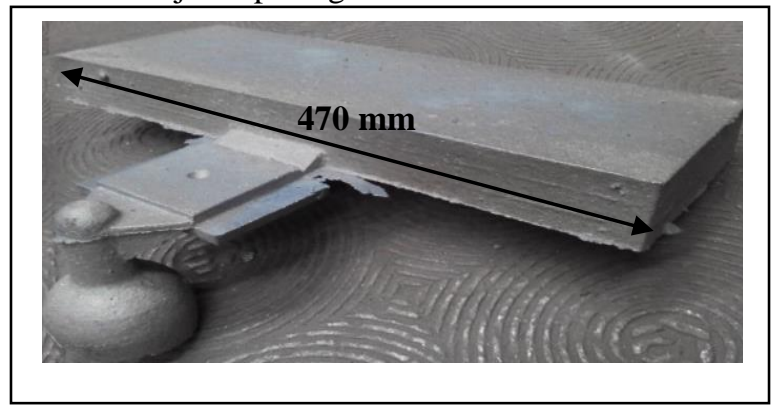

Gambar 9 benda cor yang dihasilkan

\section{IV.6. Hasil Data Logger Pada Percobaan Dengan} Flushing Time 5 Detik

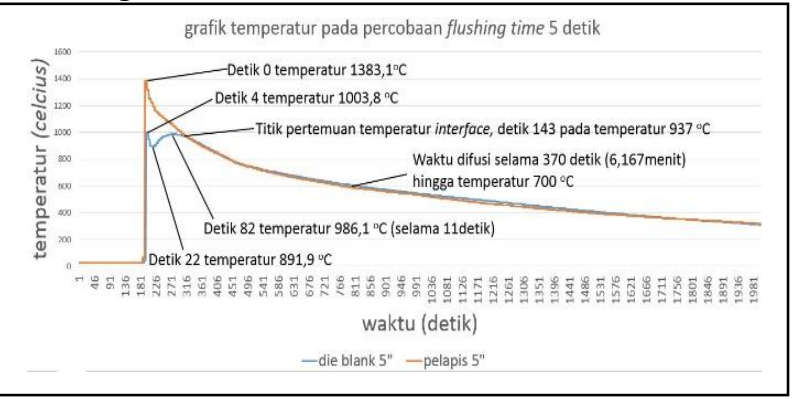

Gambar 10. Grafik temperatur pada percobaan flushing time 5 detik

Dari hasil percobaan yang disajikan pada gambar 10, dengan flushing time 5 detik didapatkan temperatur interface $937^{\circ} \mathrm{C}$ (76,57\% TL) dicapai 143 detik setelah cairan logam pertama kali dicor pada cetakan. Waktu difusi terjadi selama 370 detik (6,167 menit).

\section{IV.7. Hasil Data Logger Pada Percobaan Dengan Flushing Time 25 Detik}

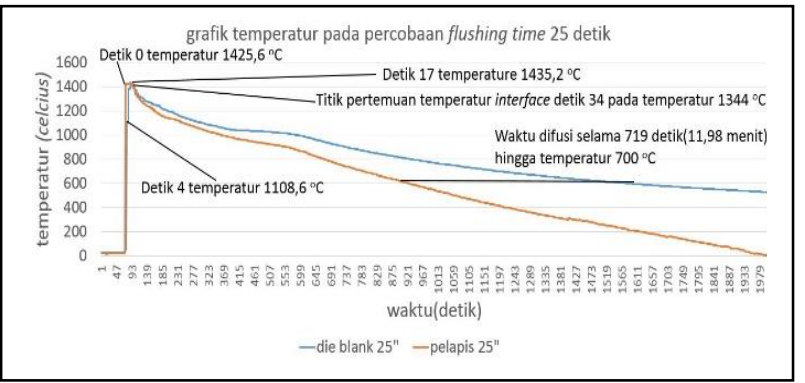

Gambar 11. Grafik temperatur pada percobaan flushing time 25 detik

Dari hasil percobaan dengan flushing time 25 detik yang disajikan pada gambar 11 , temperatur interface dicapai detik ke 34 pada temperatur $1344{ }^{\circ} \mathrm{C}$ (melebihi 
$\mathrm{TL}=1225^{\circ} \mathrm{C}$ indikasi die blank mencair $)$. Waktu difusi terjadi selama 719 detik (11,98 menit).

\section{IV.8. Penyimpangan Temperatur Interface Terhadap Flushing Time Hasil Simulasi vs Aktual}

Data logger yang digunakan hanya memiliki 4 slot thermocouple, sedangkan dalam sebuah cetakan diperlukan dua thermocouple yang ditempatkan pada die blank dan pada pelapis, sehingga data logger hanya bisa mengukur untuk 2 cetakan. Oleh karena keterbatasan alat, pada percobaan ini, thermocouple ditempatkan hanya pada cetakan dengan flushing time 5 dan 25 detik. Penempatan thermocouple pada batas bawah dan batas atas penelitian ini bertujuan agar hasil temperatur interface yang dibaca oleh data logger dapat dibuat linear, karena hasil simulasi menggunakan solidcast juga menunjukkan hubungan flushing time dengan temperatur interface berupa regresi linear yang memiliki nilai $\mathrm{r}^{2}=0,9012$ (keterkaitan positif kuat).

Grafik penyimpangan temperatur interface hasil simulasi dengan hasil percobaan (linear) disajikan pada gambar 12 berikut ini:

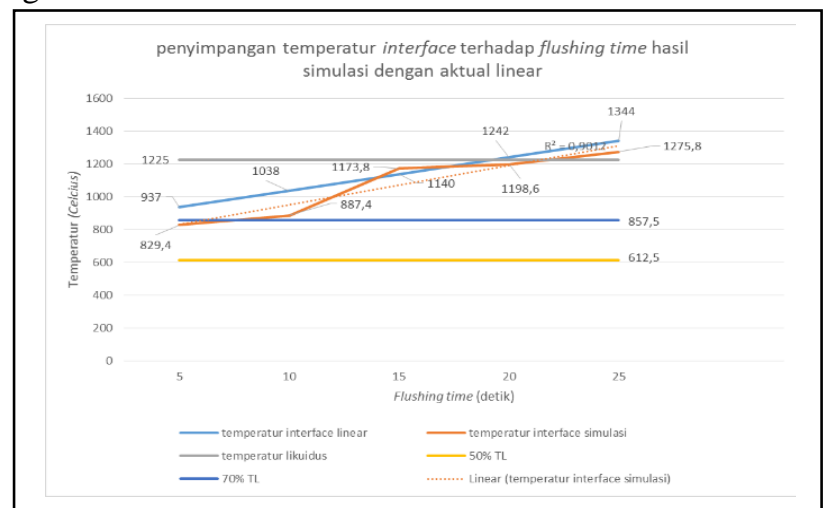

Gambar 12 Penyimpangan temperatur interface hasil simulasi dengan hasil percobaan (linear)

\section{IV.9. Mikrostruktur Pada Flushing Time 5 Detik}

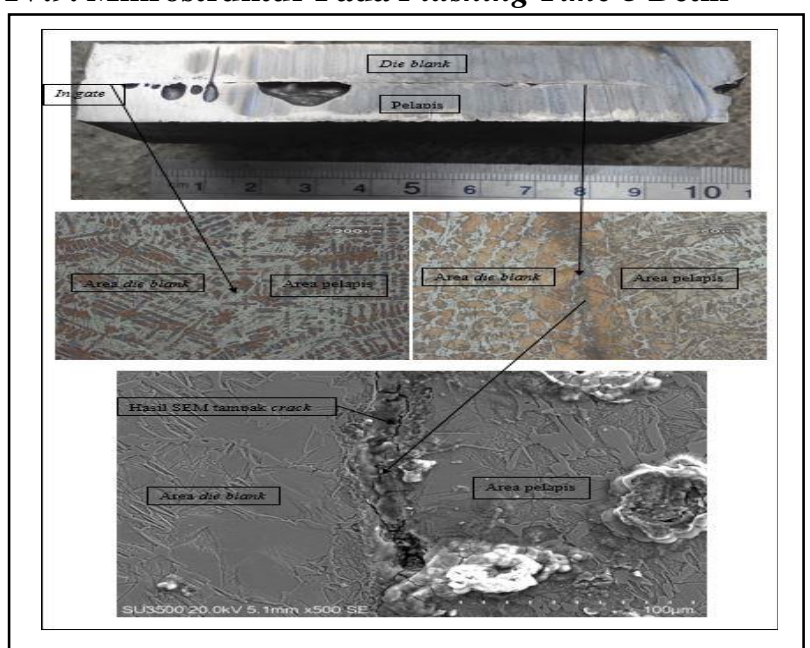

Gambar 13 Penampang potong dan struktur mikro pada flushing time 5 detik

Potongan hasil gerinda tampak garis interface di sepanjang penampang potong dan tidak tampak pada area ingate. Setelah sampel diampelas, dipoles, dietsa menggunakan nital 3\% selama 5 detik dan di lihat di bawah mikroskop, pada area ingate tidak tampak garis sambungan difusi. Pada area yang tampak garis pada interface, tampak seperti terjadi ikatan antara die blank dan pelapis. Untuk memastikan terjadi atau tidaknya ikatan difusi pada garis interface tersebut, dilakukan pengujian menggunakan SEM (Scanning Electron Microscope). Hasil SEM menunjukkan bahwa pada area tersebut tidak terjadi ikatan, terdapat gap antara die blank dan layer yang dipenuhi oleh pengotor.

\section{IV.10. Mikrostruktur Pada Flushing Time 10,15 dan 20 Detik}

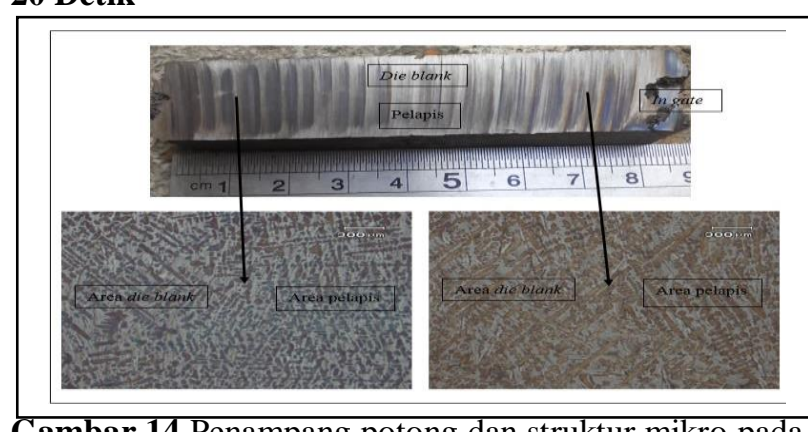

Gambar 14 Penampang potong dan struktur mikro pada flushing time 10 detik

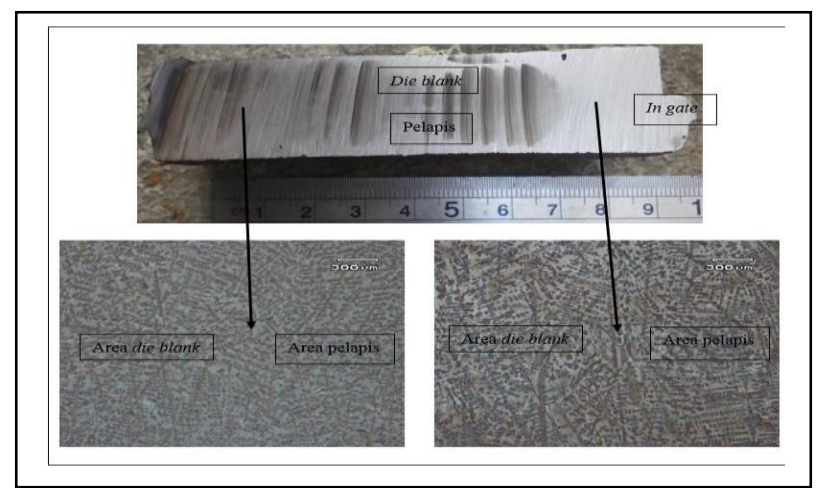

Gambar 15. Penampang potong dan struktur mikro pada flushing time 15 detik

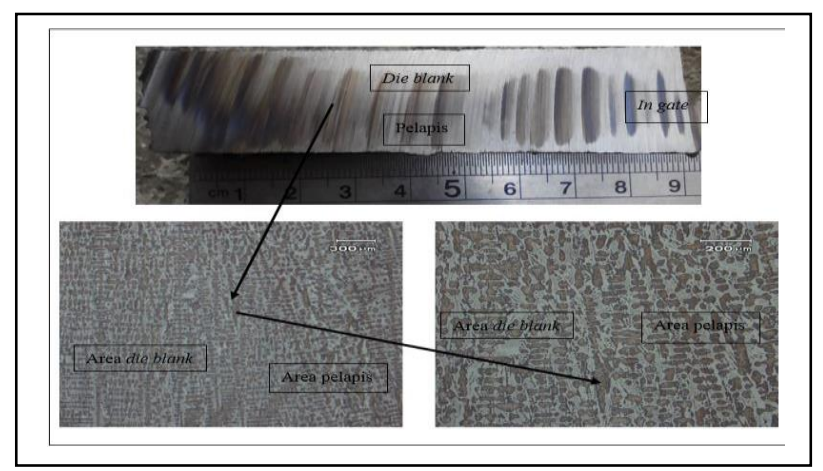

Gambar 16. Penampang potong dan struktur mikro pada flushing time 20 detik

Dari hasil potongan kemuadian dilakukan proses gerinda pada sampel dengan flushing time $10-20$ detik yang disajikan pada gambar 14,15,16 tidak tampak garis interface antara die blank dan pelapis. Terlihat ikatan yang sangat baik, orientasi struktur mikro tampak 
menyatu antara die blank dan pelapis. Pertumbuhan koloni eutektik baik edgewise growth atau cooperative growth menyatu dengan baik, material tersebut seperti dibuat dengan cara satu kali proses pengecoran,

\section{IV.11. Mikrostruktur Pada Flushing Time 25 Detik}

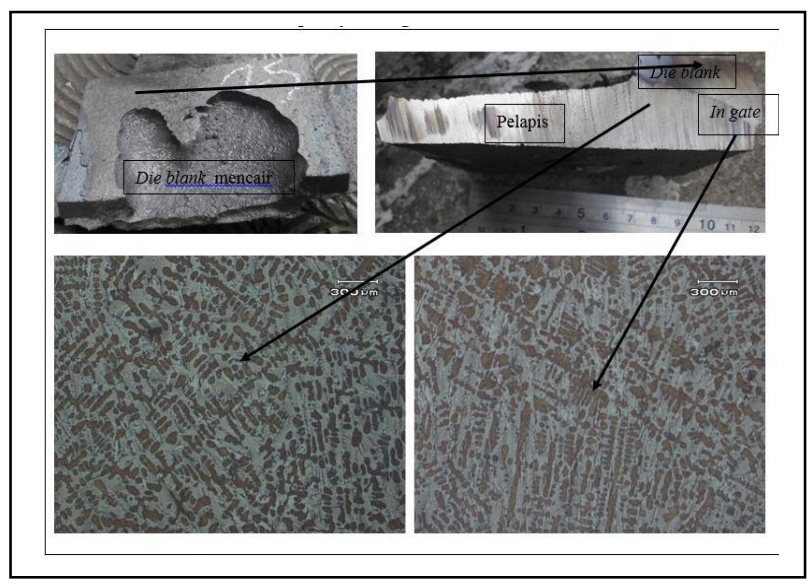

Gambar 17 Penampang potong dan struktur mikro pada flushing time 25 detik

Pada gambar 17 terlihat die blank mencair akibat menerima panas dari proses flushing. Pada gambar 11 grafik hasil pengukuran data logger menunjukkan pada detik ke 34 die blank berada pada temperatur $1344^{\circ} \mathrm{C}$ (melebihi TL $=1225^{\circ} \mathrm{C}$ ) sehingga indikasi die blank mencair terbukti oleh hasil percobaan yang dilakukan. Setelah dilakukan pengujian mikrostruktur di area die blank yang tidak mencair, tampak ikatan yang identik dengan percobaan pada flushing time 10 - 20 detik.

\section{IV.12. Pengujian kekerasan}

Dari hasil pengujian kekerasan pada keseluruhan sampel, menunjukkan bahwa hasil kekerasan sampel berada pada batas kekerasan standar (56 - 63 HRC). Temperatur interface yang dipengaruhi oleh flushing time tidak mempengaruhi kekerasan sampel, sehingga originalitas material dapat terjaga. Hasil pengujian kekerasan disajikan pada tabel 2 berikut ini:

Tabel 2. Hasil pengujian kekerasan

\begin{tabular}{|l|r|r|r|r|r|r|r|r|}
\hline \multicolumn{8}{|c|}{ PENGUJIAN KEKERASAN MENGGUNAKAN ROCKWELL C DENGAN BEBAN $150 \mathrm{Kg}$} \\
\hline Sampel & \multicolumn{3}{|c|}{ AREA DIE BLANK } & \multicolumn{5}{|c|}{ AREA PELAPIS } \\
\hline flushing time(detik) & 1 & 2 & 3 & RATA-RATA & 1 & 2 & 3 & RATA-RATA \\
\hline 5 & 54,2 & 57,3 & 57,5 & 56,33 & 55 & 56,6 & 60,5 & 57,37 \\
\hline 10 & 59,6 & 57,9 & 57,9 & 58,47 & 56,1 & 56,7 & 57,3 & 56,70 \\
\hline 15 & 55,8 & 56,3 & 56 & 56,03 & 57,4 & 56,4 & 56,3 & 56,70 \\
\hline 20 & 56 & 56,4 & 55,6 & 56,00 & 57,4 & 56,6 & 55,5 & 56,50 \\
\hline 25 & 57,4 & 58,7 & 60,5 & 58,87 & 60,7 & 60,7 & 59,8 & 60,40 \\
\hline
\end{tabular}

\section{PENUTUP}

\section{Kesimpulan}

Hasil penelitian menunjukkan bahwa pelapisan ulang Ni-Hard 1 dengan metoda grafity casting dapat dilakukan pendekatan pada benda asli grinding roll dengan variabel temperatur interface yang harus dicapai antara $1038{ }^{\circ} \mathrm{C}$ (flushing time 10 detik) - $1242{ }^{\circ} \mathrm{C}$ (flushing time 20 detik), karena ketika temperatur interface $937^{\circ} \mathrm{C}$ (flushing time 5 detik) hanya terjadi ikatan di sebagian kecil sampel, sedangkan pada saat temperatur interface $1344{ }^{\circ} \mathrm{C}$ ( flushing time 25 detik) die blank yang dilapisi mencair. Temperatur pouring antara $1438{ }^{\circ} \mathrm{C}-1468{ }^{\circ} \mathrm{C}$ agar memberikan energi panas yang cukup untuk memanaskan die blank. selain itu juga untuk menjaga keenceran cairan logam, jika temperatur cor terlalu rendah dapat menyebabkan pelapis membeku terlalu cepat sehingga proses flushing tidak optimal. Dari hasil pengujian struktur mikro pada sampel dengan flushing time 10 - 20 detik antara die blank dan pelapis terjadi ikatan yang sempurna, tidak tampak garis difusi pada area interface, pertumbuhan koloni eutektik, edgewise dan cooperative growth saling berikatan. Hasil pengujian kekerasan dan struktur mikro menunjukkan hasil sesuai dengan standar, kekerasan 56-63 HRC dengan matriks karbida eutektik, dan martensit.

\section{DAFTAR PUSTAKA}

[1] Mahendiran, G., V. Balasubramanian, T. Sethilvelan. (2011). Mechanical and metallurgical properties of diffusion bonded AA2024 aluminium alloy and commercial grade copper. Elixir International Journal, Elixir Mech. Engg. 38, 42834289.J. Moran, Michael and Shapiro, H.N., Fundamentals

[2] Rusnaldy. (2001). DIFFUSION BONDING : AN ADVANCED OF MATERIAL PROCESS. ROTASI - Volume 3 Nomor 1

[3] Cholewa, M., T. Wrobel, S. Tenerowicz. (2010). Bimetallic layer castings. Journal of Achievments in Materials and Manufacturing Engineering, volume 43, issue $1 / 2010$

[4] NIDI, NI-HARD Material Data and Applications. NIDI Publisher.

[5] ASM Handbook Volume 15 : Casting (1998), ASM International

[6] Laird, George., Gundlach, Richard., dan Klaus Röhrig (2000): Abrasion Resistant Cast Iron Handbook, American Foundry Society

[7] Vincent Gaspersz, (1995): Teknik Analisis Dalam Penelitian Percobaan, Tarsito Bandung

[8] Walton, Charles F., Opar, Timothy J.(1981): Iron Castings Handbook, Iron Casting Society, Inc. 